\title{
CRUCE DE IDENTIDADES: MASCULINIDAD, FEMINIDAD, RELIGIÓN, CLASE Y JUVENTUD EN LA JOC DE LOS AÑOS SESENTA'
}

\section{Crossed identities: Masculinity, femininity, religion, class and youth in the YCW during the sixties}

\author{
MÓNICA MORENO SECO² \\ Universidad de Alicante \\ monica.moreno@ua.es
}

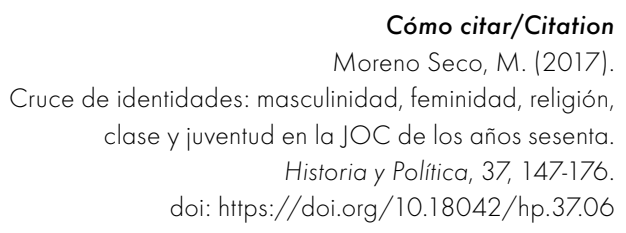

(Recepción: 30/05/2016. Evaluación: 11/07/2016. Aceptación: 07/12/2016. Publicación: 26/05/2017)

\section{Resumen}

En una época de destacados cambios sociales, tensiones políticas y crisis religiosa como la década de los sesenta, la evolución de las identidades de género en la JOC (Juventud Obrera Cristiana) estuvo marcada por la intersección con otros referentes identitarios como la clase, la religión y la juventud. En esta relevante organización de Acción Católica, la feminidad y la masculinidad se construyeron de manera cruzada, primero desde el discurso de la complementariedad y con el tiempo a partir

1 Este artículo se integra en el proyecto HAR2012-32539, «Discursos e identidades de género en las culturas políticas de la derecha española, 1875-1975», financiado por el Ministerio de Economía y Competitividad.

2 Código Orcid: 0000-0002-3219-8790. 
de propuestas que reclamaban la igualdad entre mujeres y hombres. La experiencia del trabajo, el compromiso cristiano y la rebeldía juvenil introdujeron profundas transformaciones en las identidades de género de las y los militantes de JOC, y se vieron influidas también por el cambio del discurso religioso que originalmente apelaba a la reconquista católica de la sociedad, pero después transitó hacia el diálogo con otras culturas políticas y la participación en las movilizaciones sociales y políticas que socavaron las bases de la dictadura franquista.

\title{
Palabras clave
}

Género; catolicismo; clase; juventud; franquismo.

\begin{abstract}
In the sixties, an age of profound social change, political tensions and religious crisis, the evolution of gender identities in the YCW (Young Christian Workers) was influenced by intersectionality with other categories such as class, religion and youth. In this relevant Catholic Action organization, femininity and masculinity were constructed in relation to each other, first from complementarity discourse and then from the demand for equality between women and men. Work experience, Christian commitment and juvenile rebellion led to significant changes in the gender identities of YCW militants. These identities were also influenced by a change in religious discourse which originally sought a Catholic reconquest of Spanish society but moved towards dialogue with other political cultures and participation in the social and political movements which were undermining the francoist dictatorship.
\end{abstract}

\section{Keywords}

Gender; Catholicism; Class; Youth; Francoism. 
I. INTRODUCCIÓN. II. CATÓLICOS Y CATÓLICAS DEL MUNDO OBRERO EN DEFENSA DE LA RELIGIÓN. III. JÓVENES EN EL MOVIMIENTO OBRERO. IV. CONCLUSIONES. BIBLIOGRAFÍA.

\section{INTRODUCCIÓN}

La historiografía actual entiende las identidades como construcciones históricas, sujetas a variaciones en el tiempo, y como categorías inestables que se ven sometidas a modulaciones complejas, derivadas de la intersección entre distintos elementos identitarios ${ }^{3}$. En este trabajo proponemos una aproximación a dicha cuestión desde el estudio de las identidades presentes en la JOC (Juventud Obrera Cristiana), movimiento vinculado a la Acción Católica, en la década de los años sesenta. Nos interesa analizar cómo los discursos religiosos fueron reformulados por los y las jocistas, observar de qué manera las experiencias y prácticas militantes crearon lazos identitarios y trazar la evolución de los ideales femeninos y masculinos en el seno de una organización católica pero también obrera y juvenil, durante una época de destacados cambios sociales y religiosos. A pesar de que la mayoría de estudios sobre la JOC abordan proyectos, actuaciones e iniciativas de hombres, aunque a veces hagan alusión a las militantes ${ }^{4}$, las reflexiones desde una perspectiva de género se han centrado en especial en las jocistas 5 . Nuestro punto de partida coincide con Sohn (2013), quien, remedando la clásica pregunta de si es posible la Historia sin las mujeres, insiste en incorporar al relato histórico los hombres y la masculinidad, que desde una perspectiva de género entiende que los hombres son sujetos sexuados ${ }^{6}$. Por tanto, creemos importante integrar las nociones de masculinidad y feminidad, siempre en relación mutua, en el estudio de los movimientos católicos en general, y de la JOC en particular, planteamiento que sustenta este artículo.

Abordar las variaciones experimentadas en las identidades de género en la JOC de los años sesenta ofrece la oportunidad de conocer cómo sus militantes

\footnotetext{
Pérez Ledesma (2008).

Castaño Colomer (1978) y Fernández Segura (2005): 307-444.

Martínez Hoyos (2001) y Moreno Seco (2016).

6 Una definición de la noción de masculinidad en Connell (2003), autor que además insiste en que esta categoría interactúa con la raza y la clase.
} 
conjugaron la influencia de la moral católica o el ideal de la domesticidad con la experiencia del trabajo, el compromiso cristiano o la rebeldía juvenil. Se observará el paso de planteamientos organicistas en el ámbito social y de discursos diferenciadores de género a propuestas que cuestionaron el sistema socio-económico y reclamaron la igualdad entre mujeres y hombres. Todo ello permitirá reflexionar sobre las tensiones entre las identidades de género y de clase en las jocistas, o de género y religión en los jóvenes de JOC, entre otras.

La elección de la década de los sesenta obedece a que representó el momento de mayor expansión del movimiento jocista y una época de fuertes transformaciones en la sociedad española y en el cristianismo occidental. La historiografía europea ha señalado la crisis religiosa de los sesenta como central en la investigación sobre el cambio religioso y la secularización en el siglo XX, aunque no hay acuerdo sobre su alcance. La introducción de la perspectiva de género en el estudio sobre la secularización ha dado lugar a numerosas investigaciones, centradas sobre todo en el siglo XIX y la primera mitad del $\mathrm{XX}^{8}$. La secularización se tradujo, según los primeros trabajos, en un proceso de feminización de la religión a lo largo del siglo XIX — plasmado en fenómenos como una mayor asistencia de mujeres a las prácticas religiosas, el incremento de órdenes religiosas femeninas o la extensión de expresiones piadosas vinculadas a emociones atribuidas a las mujeres-, proceso que contrastaba con el alejamiento de los hombres de los ámbitos religiosos?. Se ha subrayado también que la identificación simbólica de la religión como un elemento característico de la feminidad alentó a las mujeres cristianas a movilizarse contra la secularización, y se convirtió en argumento de menoscabo de la religión por parte del anticlericalismo ${ }^{10}$.

Como indican Muller y Favier (2013), el interés por rescatar las iniciativas religiosas de las mujeres dejó en el olvido, de manera paradójica, las experiencias religiosas masculinas. Para solventar este problema, nuevos estudios cuestionaron la tesis de la feminización de la religión al insistir en la persistente presencia de hombres en ciertas manifestaciones religiosas - la Acción Católica, entre otras-, el esfuerzo desplegado por la Iglesia hasta bien entrado el siglo Xx por remasculinizar la religión para prestigiarla o la influencia de los discursos religiosos en la definición de la masculinidad ${ }^{11}$. En la actualidad, se reclama abordar de forma más dinámica y menos rígida las relaciones entre

A partir del libro de McLeod (2007).

8 Buenos estados de la cuestión en Pasture (2012) y Mínguez Blasco (2015), a quienes seguimos en parte en los dos siguientes párrafos.

$9 \quad$ Entre otros, Fouilloux (1995).

10 Para España, Blasco Herranz (2005) y Salomón Chéliz (2011).

11 Werner (2011). 
género y cristianismo. Mínguez (2015: 418) concluye que no es posible identificar de manera mecánica los procesos de modernidad, secularización y feminización, sino que es preferible plantear en su complejidad las relaciones entre modernidad y pervivencia de la religión y de los hombres religiosos en el espacio público. Es más, se ha propuesto partir de la existencia de representaciones plurales de feminidad y masculinidad cristianas, y de feminizaciones y masculinizaciones en función del contexto ${ }^{12}$.

En cuanto a los años sesenta, mientras algunos estudiosos como McLeod (2012) consideran que fue una época de cambio intenso pero culminación de una evolución gradual, otros como Brown (2010) defienden que fue un momento de ruptura. Se ha subrayado la influencia en esta crisis religiosa de factores como las novedades políticas impulsadas por el Mayo del 68, el rechazo de las mujeres al ideal tradicional de feminidad y la emergencia de una cultura juvenil rebelde, se consideren elementos centrales o simplemente contextuales de dicha crisis ${ }^{13}$. También se ha apuntado, para el catolicismo, la importancia del Concilio Vaticano II, por su reconocimiento del mundo moderno y la aceptación de la pluralidad. Como resultado de este proceso, tuvo lugar tanto una recomposición del discurso y la acción religiosos, como su pérdida de visibilidad y capacidad de influencia. Por otro lado, la segunda ola del catolicismo progresista, en términos de Horn (2015), que tuvo lugar en los años sesenta y setenta con la radicalización del catolicismo después del Vaticano II, fue un fenómeno transnacional que coincidió además con la aparición de la nueva izquierda. Se ha concluido que la crisis religiosa que comenzó en los sesenta borró las fracturas de tipo religioso en términos de clase o género, ya que afectó a toda la sociedad, de manera que el compromiso o el rechazo a la religión se convirtieron en fenómenos individuales ${ }^{14}$.

A la luz de estos debates y aportaciones, centrados fundamentalmente en la Europa septentrional y occidental, se pretende reflexionar sobre la reconfiguración de las identidades de género en el avance de la secularización en la España de los sesenta, un proceso similar al de otras sociedades occidentales a pesar de las diferencias políticas ${ }^{15}$, a partir del estudio de un movimiento que formaba parte de la Iglesia, pero muy permeable a factores externos por su vinculación con la cultura católica conciliar y por sus contactos con la JOC internacional. Como categorías relacionales, la feminidad y la masculinidad

12 También Pasture (2012): 32-33.

13 Brown (2013) concede especial relevancia al cambio de actitud de las mujeres jóvenes ante la religión.

14 McLeod (2010): 37.

15 Como sostiene Cazorla-Sánchez (2013). Un estado de la cuestión sobre la secularización, especialmente útil para la historiografía española, en De la Cueva Merino (2015). 
se reelaboraron de manera cruzada en la organización jocista, primero desde la rígida separación entre un movimiento masculino (JOC) y otro femenino (JOCF), sustentada en un discurso de la complementariedad, y más adelante con una creciente colaboración que condujo a la fusión de ambos en una JOC mixta y en la extensión de un discurso de la igualdad.

Por un lado, las novedades religiosas y culturales de los sesenta supusieron para muchas católicas el fin de la tradicional armonía entre la identidad religiosa y la feminidad, con la irrupción de demandas feministas, la difusión de nuevos principios morales y la aprobación de reformas conciliares que revalorizaron la acción de las mujeres, pero también con el malestar que provocaron los límites a los cambios en la Iglesia católica — por la negativa a aceptar el sacerdocio femenino o los métodos anticonceptivos, por ejemplo- Las respuestas fueron muy diversas, pero parte de las católicas optaron por vías que reformularon la identidad religiosa femenina, como el compromiso social, la demanda de mayor reconocimiento dentro de la Iglesia y en ocasiones el abandono de la estructura eclesiástica ${ }^{16}$. Por otro lado, estas transformaciones también afectaron a los católicos, cuya evolución no es tan conocida desde un punto de vista de género ${ }^{17}$. Habría que valorar el impacto de las nuevas costumbres, el cuestionamiento de la castidad que trajo consigo la liberación sexual, el acceso de las mujeres a espacios hasta ese momento masculinizados o la introducción de la doctrina conciliar, que matizó los valores de jerarquía y diferencia sexual, factores que necesariamente modificaron la identidad religiosa masculina, aunque no pueda olvidarse la pervivencia de la autoridad masculina en el clero.

Este panorama se vuelve más complejo si a las identidades de género y religión añadimos la categoría de clase. El carácter netamente obrero de ambas organizaciones (JOC/F) introdujo modulaciones importantes en la concepción de la masculinidad y la feminidad católicas, pues se impregnaron de valores propios del mundo del trabajo ${ }^{18}$. Una cultura obrera profundamente masculinizada, que representaba en masculino el ideal del trabajador y ocultaba la experiencia de las obreras ${ }^{19}$, pero que desde mediados de los sesenta se mostró

16 Favier (2009); Moreno Seco (2003), y Valiente (2007).

$17 \mathrm{La}$ influencia de los cambios sociales que, en términos generales, cuestionaron los privilegios masculinos y provocaron crispaciones identitarias que afectaron a los hombres en Rauch (2004): 179-189 y 209-227.

18 Debido a la extensa producción investigadora sobre las relaciones entre clase y género, preferimos remitir a las recientes e interesantes reflexiones de Arbaiza (2014) sobre la cambiante evolución de la masculinidad y la feminidad obreras.

19 Muñoz Ruiz (2007) y Varo Moral (2014): 92-96. 
más receptiva a la presencia de mujeres ${ }^{20}$. En un contexto de crisis religiosa y de un compromiso laboral y antifranquista absorbente, afloraron las tensiones entre el ideal de masculinidad católica y el arquetipo masculino obrero, así como entre una identidad femenina obrera de jóvenes preparadas para el hogar y otra de trabajadoras autónomas que asumían responsabilidades sindicales y políticas.

Por último, la categoría de juventud también se erigió en un elemento fundamental en la conformación y evolución de las identidades en la JOC/ $\mathrm{F}^{21}$. En los años sesenta confluyeron la irrupción de una nueva generación que no había vivido la Guerra Civil y se percibía como diferente de sus mayores, con el desarrollo de una cultura juvenil internacional, que marcó la JOC de manera especial por sus contactos con el exterior ${ }^{22}$. A pesar de las dificultades que entraña estudiar los movimientos juveniles, por el carácter transitorio de su militancia ${ }^{23}$, puede apuntarse que los y las jocistas compartían con el resto de la juventud española nuevos referentes simbólicos y culturales, evolucionando hacia una incorporación plena de nuevas costumbres y formas novedosas de concebir las relaciones personales, que cuestionaron las bases de la moral nacional-católica ${ }^{24}$. Además, se trató de una juventud cada vez más indiferente en materia religiosa y progresivamente politizada, con la irrupción de la nueva izquierda y el auge de proyectos progresistas, que en España se tradujo en la oposición a la dictadura franquista ${ }^{25}$.

\section{CATÓLICOS Y CATÓLICAS DEL MUNDO OBRERO EN DEFENSA DE LA RELIGIÓN}

La JOC surgió en Bélgica en 1919, aunque adoptó dicha denominación en 1925. En España, los primeros grupos jocistas aparecieron en el periodo de

20 Como sucedió en la cultura comunista del momento, Erice Sebares (2010).

21 Ha teorizado sobre la juventud Souto Kustrín (2007). En el dosier coordinado por Moreno y Ortuño (2015), se propone avanzar en el análisis de la intersección entre género, juventud y compromiso.

22 A juicio de Marwick (1998: 17-18), entre las características de los sesenta se encuentran la novedosa influencia de la juventud, con subculturas juveniles que impactaron en toda la sociedad, la circulación internacional de ideas, la liberación sexual y los cambios en la moral.

23 Domènech Sampere (2008): 39.

24 Un estudio sociológico en Martín Serrano (1994): 33-38 y 85-86. El orden de género franquista se vio muy afectado en los años sesenta por fenómenos como el turismo, como ha demostrado Nash (2015).

25 Interesantes reflexsiones en Martín et al. (2009). 
entreguerras, pero el movimiento no se consolidó hasta mediados de los años cuarenta, mientras la JOCF vio la luz a principios de los cincuenta. Ambos se insertaron en la Acción Católica, una organización de largo recorrido que se remontaba a la década de los veinte, impulsada por la jerarquía eclesiástica como reacción ante la secularización. Si se ha interpretado la Acción Católica como parte del esfuerzo por remasculinizar la religión, con el recurso a metáforas viriles para movilizar a sus militantes - considerados soldados de Cristo-, también se ha matizado esta afirmación, recordando las diferencias con otros elementos de la masculinidad normativa — de la que se distinguía por la insistencia en la obediencia, el sacrificio o la compasión- y la destacada incorporación de mujeres a tareas sociales y políticas de la $\mathrm{AC}$, que reformuló la identidad femenina católica tradicional, introduciendo elementos simbólicos como el valor ${ }^{26}$. En ese sentido, Van Osselaer insiste en que, a pesar de la delimitación de virtudes masculinas y femeninas en la AC, tanto mujeres como hombres podían percibirse como defensores/as de la religión, con atributos que a veces presentaban perfiles menos rígidos de lo esperado ${ }^{27}$.

En el primer franquismo, la Acción Católica española estuvo impregnada del espíritu de reconquista política, restauración social y recristianización religiosa propio del nacional-catolicismo ${ }^{28}$. De acuerdo con los ideales diferenciados de feminidad y masculinidad católicas del momento y con el discurso de la complementariedad entre los sexos, la actividad desplegada por los hombres se centraba en la política, mientras las mujeres priorizaban la acción benéfica y el control moral. Los discursos de movilización espiritual y retórica triunfante se plasmaron en iniciativas como la peregrinación a Santiago organizada por los Jóvenes de Acción Católica en 1945, que fue planteada como prueba de demostración de virilidad y capacidad de sacrificio ${ }^{29}$. Sin embargo, el carácter genuinamente obrero de la JOC/F y el recurso a una formación que invitaba a sus militantes a reflexionar sobre su propia realidad y adquirir compromisos concretos de acuerdo con la metodología del ver-juzgar-actuar, permitieron su evolución ${ }^{30}$.

A principios de la década de los sesenta, la JOC/F estaba extendida por todo el país ${ }^{31}$. En estos años predominaban en el movimiento las identidades

\footnotetext{
Van Osselaer (2009) y Blasco Herranz (2003).

Van Osselaer (2013): 29-30, 194-195 y 216-221.

Louzao y Montero (2015).

Vincent (2015).

30 Sanz Fernández (1994). Se transformó en este sentido de manera muy marcada el movimiento de obreros adultos, la HOAC (López García, 1995).

31 La JOC contaba con unos 15.000 militantes en 1960, según Castaño Colomer (1978): 221.
} 
de género, religiosa y obrera, mientras la juventud era percibida como una etapa de paso a la edad adulta. Tanto JOCF como JOC mostraron interés por la definición de la virilidad y la feminidad en los ámbitos de trabajo, en los momentos de ocio y en las relaciones personales, desde planteamientos que naturalizaban la diferencia sexual y fundamentaban la complementariedad ente mujeres y hombres, como veremos a continuación.

Los militantes de JOC aparecían todavía en los primeros años sesenta como herederos del anterior espíritu triunfal y de recristianización, afianzado por la retórica masculina juvenil: en 1960 se definía a los jocistas como «firmemente seguros de poseer la verdad y de estar en la posición justa ante los hechos de la vida. Con virilidad juvenil, con orgullo de estar haciendo algo grande por todos, (...) los jóvenes avanzan con ímpetu a la conquista del mañana $»^{32}$. Partían de una concepción elitista de la acción apostólica, pues los jocistas se percibían como líderes obreros. Unas características que tampoco eran privativas de la acción social española, sino propias del catolicismo social europeo del momento. El fundador de la JOC, el sacerdote belga Cardijn, en una visita a España se dirigió al Congreso Nacional de la Juventud Obrera declarando: «adelante, a la conquista de todos los jóvenes trabajadores ${ }^{33}$.

Los jocistas eran invitados a asumir el ideal masculino que encarnaba su boletín, que — se decía - por ser joven tenía ilusión, empuje y valentía; por ser obrero era duro, sencillo, concreto, con ganas de que las cosas cambiaran, y por ser cristiano era "veraz, sincero, cariñoso, defensor de la justicia, viril, realista, amante de Dios y de los hombres $\rangle^{34}$. Estos tres elementos, que definían la manera de ser un hombre para los militantes de JOC, muestran que su arquetipo de masculinidad se distinguía del arquetipo laico por su insistencia en una virilidad mística, espiritual y militante, en lo que se ha denominado un planteamiento particular y paradójico ${ }^{35}$. Por ello se aludía a la acción de los jocistas «sin beaterías, ni ñoñeces, con virilidad y sentido de la vida real, con la conciencia clara de nuestros problemas y de las soluciones para los mismos», en un intento por alejarse de la imagen feminizada e infantilizada de la reli-

32 Juventud Obrera, núm. 37, enero de 1960. Este boletín pertenecía a la JOC pero estaba abierto a la colaboración de militantes de la JOCF y tuvo una gran difusión, lo que le convierte en una fuente privilegiada para estudiar las identidades y representaciones jocistas.

33 Un congreso al que asistieron 10000 jóvenes de ambos sexos (Juventud Obrera, número extraordinario, julio de 1960).

34 Juventud Obrera, núm. 56, agosto de 1961.

35 Muller y Favier (2013). 
gión $^{36}$. En el mismo sentido, cabe destacar la preocupación manifestada en la JOC ante el paso de sus militantes por el servicio militar, que condujo a crear una sección especializada en la organización ${ }^{37}$. El servicio militar era considerado como un momento de prueba de los jocistas, que debían demostrar la fortaleza de su fe, de su compromiso y de su moral, ante las probables críticas que podían cuestionar su masculinidad por sus creencias religiosas ${ }^{38}$ y su autocontrol moral, o que simplemente censuraban su interés social; ante este tipo de circunstancias, se apelaba al valor y entrega de los jocistas para mantener criterios propios "sin ser un tipo raro o un 'santón'»39.

Pero el ideal viril de JOC también se diferenciaba del arquetipo masculino del mundo obrero, pues aunque ambos modelos compartían algunos principios - compañerismo, solidaridad, esfuerzo, dignidad del trabajo-, se distancian en otros como el anticlericalismo o la sexualidad explícita ${ }^{40}$. Por ello se llamaba a los jocistas a que educaran su voluntad en la castidad, «en la energía de una pureza viril y de un renunciamiento constante», en el respeto a sus futuras esposas ${ }^{41}$. Por otro lado, no se entendían la fe y la movilización contra las injusticias sociales como excluyentes: en 1963, el presidente de la JOC, José Antonio Alzola, sostenía que «como hombre y como cristiano tengo el deber de luchar contra la injusticia y contra el pecado», a pesar de los riesgos y dificultades que entrañaba, ofreciendo una lectura épica de la militancia ${ }^{42}$. La interpretación que sustentaba la organización era que sus militantes demostraban su virilidad desafiando las normas y los códigos obreros y laicos al mantener sus rasgos específicos. En ese sentido, en 1964, se afirmaba de manera explícita: «Ya no cabe hablar de que el cris-

36 Como se afirmó en el Congreso Nacional de la Juventud Obrera (Juventud Obrera, núm. 44, agosto de 1960).

37 Críticas al autoritarismo, exceso de tiempo libre e inmoralidad durante el servicio militar en «Balance de la encuesta mundial sobre el trabajo», Comisión Nacional de la JOC, Madrid, junio de 1964, Archivo Nacional de la JOC (ANJOC), Caja 62, carp. 1.2.

38 «Un día un compañero del servicio militar que será incrédulo o que será protestante te acosará a preguntas, te asegurará que estás equivocado y que está bien que las chicas vayan a misa, pero de ninguna manera los hombres», en JOC (1965): 103.

39 «JOC. El militante en el servicio militar. Cómo aprovechar el tiempo en la mili para nuestra promoción y la de los compañeros», sf. Arxiu Diocesà de Barcelona, Fons JOC Espanya, 3.22.1.

40 Sun (2004).

41 Según el obispo de Bilbao, Gúrpide, en su intervención en el XIV Consejo Nacional de JOC (Juventud Obrera, núm. 57, septiembre de 1961).

42 Juventud Obrera, núm. 73, mayo de 1963. 
tianismo produce hombres mutilados o disminuidos, hombres tímidos y pasivos, enemigos de toda iniciativa y de toda acción»; recurriendo a símiles guerreros, se vaticinaba que «resultarán vencedores solamente aquellos que soporten valerosamente el sufrimiento, los ultrajes, las calumnias e incluso la misma muerte» ${ }^{43}$.

La distinción entre masculinidad obrera cristiana y masculinidad laica se reforzó en estos años con el anticomunismo propio de la cultura católica, afianzado por el contexto español e internacional. En el curso 1963-1964 la JOC emprendió la campaña "Por una mayor conciencia y dignidad obrera", en que se reclamaba que cada joven operario diera una dimensión cristiana a la vida del trabajo y estuviera dispuesto a luchar por la promoción de la clase trabajadora, pero sin dejarse arrastrar por el sentido marxista de la lucha de clases, pues el cristianismo — se decía - es incompatible con el odio $^{44}$. La JOC de estos años utilizaba un lenguaje de justicia social alejado del marxismo, pero también mostraba distancia frente a la dictadura, reclamando libertad de asociación y un sindicato representativo, lo que condujo a sus militantes a participar de forma muy activa en las movilizaciones laborales, hecho que les proporcionó una imagen heroica frente a sus compañeros ${ }^{45}$.

Otra estrategia para definir la masculinidad jocista consistía en apelar a la responsabilidad, la madurez y la solidez de carácter de los jóvenes, pues hacerse hombre significaba alejarse de la infancia para asumir rasgos de la edad adulta. Se entendía la juventud masculina como una etapa de preparación para la vida adulta, animándose a «aceptar pequeñas responsabilidades y compromisos actuales para llegar cuando hombres al compromiso serio y definitivo con la vida». No obstante, esos discursos no estaban exentos de ambigüedades, y en alguna ocasión se sostuvo que la JOC/F había despertado la conciencia de muchachos y muchachas con "grupos que no son de niños 'buenos', sino de jóvenes viriles que con seguridad van hacia adelante. La feminidad y la hombría se han juntado para llevar a cabo una acción en común $»^{46}$, uniendo así a jóvenes de ambos sexos y atribuyendo de forma paradójica a las chicas características masculinas.

43 Juventud Obrera, núms. 81-82, abril-mayo de 1964.

44 JOC (1963): 27.

45 Según el testimonio de Joan Moles Benet, detenido a raíz de unas protestas en 1964 en Sabadell, entrevista citada en Fernández Segura (2005): 409. Sobre el compromiso laboral y político de la JOC y otras organizaciones católicas, vid. Berzal de la Rosa (2007); Montero (2009), y Ortiz y González (2011).

46 Juventud Obrera, núm. 44, agosto de 1960. 
Pero más frecuente fue que la virilidad de los jocistas se reafirmara por contraposición a las mujeres. En ocasiones se recurría al contraste entre arrojo y dependencia, entre fortaleza y debilidad, desde una posición paternalista que comparaba a las mujeres con delicadas y preciosas flores necesitadas de cuidados y ayuda ${ }^{47}$. En otras se describía a las mujeres en términos de belleza y simpatía, incluso cuando se aludía a dirigentes jocistas internacionales, comentarios que se omitían en el caso de los varones ${ }^{48}$. Sobre la actuación y función social de mujeres y hombres, se recurría al discurso de la complementariedad, que insistía en que unos y otras tenían distintas misiones sociales. En algunos casos se advierte cierto temor y animadversión contra aquellas que pretendían ser iguales que los hombres, recalcando que las mujeres debían descubrir «vuestro papel (y sin luchar contra nosotros, pues eso no conduce a nada) ${ }^{49}$.

La definición del ideal femenino de JOCF se caracterizó también por la complejidad. El carácter obrero de las militantes jocistas presentaba en los primeros años sesenta contornos poco precisos, pues las jóvenes trabajadoras eran percibidas con frecuencia como novias de obreros o como operarias que en un futuro próximo serían madres y esposas ${ }^{50}$. Diversas investigaciones han revelado que las jóvenes trabajadoras españolas del momento no habían desarrollado una identidad obrera sólida, debido al tipo de ocupación que desempeñaban —en la economía sumergida o con pocas posibilidades de mejora profesional—, y a que eran educadas para abandonar el trabajo al contraer matrimonio ${ }^{51}$. Tampoco el marco legislativo ayudaba, pues la Ley de Derechos Profesionales de las Mujeres de 1961, si bien contemplaba algunas mejoras laborales, no supuso una transformación de arquetipos, al sancionar la dependencia de la trabajadora al marido ${ }^{52}$. En consecuencia, en ocasiones las militantes de JOCF se planteaban tomar postura ante los pro-

47 Juventud Obrera, núm. 66, septiembre de 1962. En el mismo sentido, la actitud paternalista de las autoridades franquistas hacía recaer en los hombres la responsabilidad de estas actividades contestatarias, mientras que se eximía a las mujeres. A modo de ejemplo, a raíz de la publicación de un documento sobre Asturias de HOAC/F y JOC/F en 1962, solo fueron citados a declarar los hombres. Castaño Colomer (1978): 90-91.

48 Juventud Obrera, número extraordinario, julio de 1960.

49 Juventud Obrera, núm. 37, enero de 1960. Juventud y Trabajo, núm. 3, octubre de 1962; esta publicación dependía de la JOCF.

50 Una identidad conflictiva que compartían con las militantes de HOACF, a juicio de Moreno Seco (2011).

$51 \quad$ Babiano (2007): 26-37.

52 Nash (2010): 144. 
blemas del mundo obrero, no tanto como trabajadoras sino pensando en ayudar a sus futuros maridos obreros ${ }^{53}$. No obstante, también se ha interpretado esta situación como una elección de las propias trabajadoras, que representándose como amas de casa obtenían reconocimiento social y contribuían a la estabilidad del orden de género obrero ${ }^{54}$.

La identidad que se reforzó en estos primeros años en la JOCF, por tanto, fue la de género, que no establecía diferencias entre un modelo laico y otro religioso, pues las normas de la doctrina católica sobre el comportamiento femenino estaban muy extendidas en la sociedad española y pervivía una identificación simbólica entre feminidad y catolicismo ${ }^{55}$. El ideal de mujer jocista se sustentaba en valores como la belleza, la abnegación y la sensibilidad, que concedía a las mujeres una misión social trascendental, por «la necesidad que tiene el mundo de paciencia, de dulzura, de entrega.... ${ }^{56}$. Aunque se trataba de una misión apostólica, debía desarrollarse por medio de la humanización de la sociedad, no tanto de su conquista religiosa, por lo que no se insistía tanto como en el caso de los jocistas en la necesidad de reafirmar su identidad cristiana, que parecía darse por hecho. Las fronteras entre tareas masculinas y femeninas estaban bien delimitadas y los arquetipos se definían por contraposición: mientras la función de las mujeres requería subrayar su feminidad, pues no la «llevará a cabo pretendiendo ser como él, sino poniéndose a su lado y siendo lo más 'mujer' que le sea posible», también la sociedad necesitaba al hombre, «y no admitimos en él inclinaciones afeminadas. Nos parece que el mundo se vendría abajo si ellos dejaran de ser fuertes, conquistadores y tenacess $\$$.

A pesar de lo dicho con anterioridad, se trata de una feminidad elaborada en función de la clase social, que debía conceder respetabilidad a las mujeres de extracción obrera, en torno a valores como el autocontrol moral, el espíritu maternal, la generosidad o la limpieza ${ }^{58}$. Ante las críticas que en ocasiones sus compañeros vertían contra las jóvenes de clase trabajadora que concedían demasiada atención a su aspecto, las jocistas respondían recordando que ellas hacían grandes esfuerzos por cuidar su apariencia, que vinculaban a

\footnotetext{
53 «Participación femenina». Materiales de la II Asamblea Nacional INFO, Madrid, agosto de 1962, ANJOC, Caja 73, carp. 1.1.1.

54 Arbaiza (2014): 153.

55 Morcillo (2000).

56 Juventudy Trabajo, núm. 14, septiembre de 1963.

57 Juventud Obrera, núm. 64, abril de 1962.

58 Juventud Obrera, núm. 40, abril de 1960.
} 
su dignidad de clase ${ }^{59}$. En el mismo sentido, cuando eran censuradas por mantener relaciones con estudiantes $\mathrm{u}$ oficinistas, y no con obreros, se contestaba que las jóvenes de clase popular reclamaban un trato amable y cortés, pues a veces «por pareceros más varonil, [los trabajadores] tenéis para con nosotras un comportamiento inadecuado ${ }^{60}$.

Por otro lado, las jocistas pronto comenzaron a insistir en la dignidad del trabajo y en su condición de obreras, aun sin olvidar que debía ser compatible con su función primordial de madres y esposas y no debía poner en peligro su feminidad ${ }^{61}$. En este sentido, Martínez Hoyos (2001: 226) señala la contradicción de la JOCF entre la insistencia en el hogar como verdadera misión de las mujeres y su valoración del trabajo como motivo de respetabilidad y orgullo. En 1962, dando un paso más, alguna voz reclamaba ya no solo comprensión con el marido o el novio en el movimiento obrero, sino "que tomes tu puesto en la lucha, que participes directamente en aquellas actividades que te son propias, que corresponden a tu condición de mujer» y que permitan la promoción de la mujer obrera ${ }^{62}$. En este sentido, la campaña de la JOCF para el curso 1961-1962 tenía como lema "Centrar nuestra vida a partir de nuestro trabajo», una orientación que iría en aumento, en la medida en que las jocistas fueron asumiendo mayores responsabilidades laborales y participaron en movilizaciones obreras, como veremos en el apartado siguiente.

La importancia concedida a la moral y el noviazgo tanto en la JOC como en la JOCF condujo a una campaña común en el curso 1959-1960 denominada "Construyamos la familia obrera». Sus planteamientos de partida reflejaban unos presupuestos bastante conservadores en términos morales, de acuerdo con la doctrina católica del momento, con apelaciones a los jóvenes para que respetaran a sus novias y a las jóvenes para no incitar a la sensualidad, y con gran insistencia en fundar familias obreras «sanas y cristianas» ${ }^{63}$. La representación del noviazgo ideal se simbolizó en una imagen de una pareja compuesta por un obrero con mono de trabajo y una joven sin ningún atributo que aludiera a su condición de trabajadora, que caminaban por una senda de respeto, dignidad, cultura, salario, vivienda o trabajo, hacia un sol

59 Juventud Obrera, núm. 37, enero de 1960 y núm. 38, febrero de 1960. Vid. en este sentido, Llona (2007): 104.

60 Juventud Obrera, núm. 71, marzo de 1963.

61 Juventudy Trabajo, núm. 5, diciembre de 1962.

62 Juventud Obrera, núm. 65, mayo de 1962.

63 Juventud Obrera, núm. 38, febrero de 1960. 
que simbolizaba la familia obrera ${ }^{64}$. La educación sentimental de la juventud jocista implicaba concebir el amor como fuente de satisfacción y elevación para ellos, y de sacrificio y entrega feliz para ellas ${ }^{65}$. Se insistía mucho en que la falta de espacios de ocio respetable para los y las jóvenes dificultaba un trato entre ambos sexos fundado en la naturalidad, la sinceridad y el desinterés, por lo que eran frecuentes en la prensa jocista y en sus documentos internos las críticas a los bailes malsanos y los billares.

Para atajar estos problemas, JOC y JOCF crearon el servicio INFO (Institución Nueva Familia Obrera) en 1960, con el objetivo de preparar a los militantes para el matrimonio y conseguir unas condiciones de vida dignas ${ }^{66}$. La INFO organizó cursos, conferencias, actividades de ocio y comités mixtos que abordaron aspectos como el trato mixto, la moral, la misión del matrimonio o la psicología del hombre y la mujer, desde un discurso de la complementariedad ${ }^{67}$. Se insistía en que se deseaba preparar a la juventud para la familia, "pero no de una forma 'moralista' y ñoña, sino con todo el sentido varonil por parte del joven y con toda la feminidad necesaria por parte de la joven ${ }^{68}$. Las militantes de JOCF implicadas demandaban que sus opiniones fueran respetadas y «no sentirnos acomplejadas ni pensar que ellos lo harán mejor», opiniones que muestran que el trato mixto que se reclamaba no era tan sencillo en la práctica militante ${ }^{69}$. Por otro lado, la identidad obrera afloraba también, ya que la INFO insistía en que algunos problemas sociales afectaban negativamente a las familias obreras, como los bajos salarios o la falta de viviendas, lo cual condujo a solicitar mejoras a las autoridades.

\section{JÓVENES EN EL MOVIMIENTO OBRERO}

A mediados de los años sesenta la JOC/F alcanzó su momento de mayor influencia en la sociedad española, en un contexto general de auge y

64 Reproducida con cierta frecuencia en la prensa y en los materiales de formación jocista. Por ejemplo, Juventud Obrera, núm. 43, julio de 1960.

65 Juventud Obrera, núm. 68, diciembre de 1962.

66 Resumen de la I Asamblea Nacional INFO, Ávila, agosto de 1961, ANJOC, Caja 72, carp. 1.3.3.

67 Unos planteamientos que compartía con la JOC/F francesa, según Favier (2012).

68 Boletín de militantes (sf), en Materiales varios INFO, ANJOC, Caja 73, carp. 1.3.3.

69 «Participación femenina». Materiales de la II Asamblea Nacional INFO, Madrid, agosto de 1962, ANJOC, Caja 73, carp. 1.1.1. 
creciente politización de los movimientos juveniles de la Acción Católica ${ }^{70}$ : en 1964 el boletín Juventud y Trabajo logró una tirada de 12000 ejemplares y un año después Juventud Obrera lanzó 40 000, mientras la JOCF disponía de una militancia de 13000 jóvenes $^{71}$. En esta época también empezaron a vislumbrarse algunos cambios en la organización, que apuntaban a un reforzamiento de las identidades de clase y juvenil, en detrimento de la insistencia anterior en el carácter cristiano de la militancia y en los discursos de la diferencia sexual. Un debate que también atravesaba la JOC internacional, con quien existía continua relación, no solo entre dirigentes, sino también por medio de la asistencia de militantes españolas y españoles a grandes concentraciones jocistas como el Rallye Europeo de Estrasburgo (1964) y los encuentros en Bangkog (1965) y París (1967). Los Consejos Nacionales de JOC y JOCF, celebrados en agosto de 1965 en Santiago de Compostela, concluyeron que los y las militantes debían tener una presencia activa en las empresas y descubrir el compromiso temporal, pero reconocían la dificultad de mantener un equilibrio entre su carácter de movimiento obrero y de movimiento de Iglesia ${ }^{72}$. No puede olvidarse, a este respecto, que en JOCF y JOC la diversidad de opiniones era frecuente entre quienes primaban la opción temporal y quienes insistían en una postura más mística y de interiorización ${ }^{73}$.

La masculinidad jocista se presenta en esta etapa más atenuada, parece perder el anterior espíritu combativo de recristianización, aunque el compromiso temporal, que impulsó a participar en las movilizaciones obreras, suponía también ensalzar valores como la entrega, la solidaridad y el sacrificio. En noviembre de 1965 un editorial de Juventud Obrera reivindicaba el espíritu de denuncia ante las injusticias, pero también afirmaba que «la verdadera revolución es la del amor», no como "tontería emocional» sino como deseo de redención para todos los hombres. Alberto Revuelta, que había sido vicepresidente de JOC, elogiaba por esas fechas el compromiso juvenil en la lucha obrera, que «rompe pujante y vigorosa $»^{74}$. Aunque se alababa a los jóvenes comprometidos que a pesar de las dificultades y riesgos adoptaban responsabilidades, las alusiones explícitas a su virilidad fueron desapareciendo en favor del

\footnotetext{
70 Montero (1987): 119-121 y Montero (2005).

71 Juventudy Trabajo, núm. 22, mayo de 1964; Castaño Colomer (1978): 177 y Montero (2000): 261, respectivamente.

72 Juventud Obrera, núm. 98, septiembre de 1965.

73 Entrevista a Aida Fuentes Concheso, Archivo de Fuentes Orales para la Historia Social de Asturias.

74 Juventud Obrera, núm. 100, noviembre de 1965.
} 
masculino genérico, cada vez más extendido a medida que se estrechó la colaboración entre mujeres y hombres jocistas ${ }^{75}$.

En esta etapa en que la participación en las protestas obreras se incrementó de forma notable, las alusiones religiosas quedaron de forma progresiva en un segundo plano. Si los militantes de JOC subrayaban su identidad masculina religiosa, no era tanto por confrontación con el anticlericalismo del movimiento obrero, sino ante las posiciones preconciliares que les acusaban de abandonar la religión por la lucha laboral; los jocistas respondían a estas críticas reafirmando su carácter de «vigorosa juventud militante que ha escuchado con docilidad y alegría el viejo mensaje del Evangelio, remozado y puesto al día ${ }^{76}$. El anticomunismo fue difuminándose, junto con la anterior insistencia en delimitar un modelo de masculinidad diferente al laico y obrero, como resultado del entendimiento entre jocistas y comunistas en las fábricas y en la lucha laboral, aun sin dejar de subrayar su independencia, «dada nuestra dignidad de cristianos obreros» ${ }^{77}$. Los testimonios orales revelan la convivencia entre comunistas y cristianos, quienes aunque en ocasiones sintieran desprecio o fueran objeto de burla por parte de sus compañeros no creyentes, suelen insistir en el respeto que obtenían por su seriedad y compromiso ${ }^{78}$. Según José Fernández Segura (2005: 238-239), esta cooperación fue posible porque ambos grupos compartían valores como el sacrificio, la honestidad, la entrega a los demás o la solidaridad con los más desfavorecidos ${ }^{79}$.

En consecuencia, puede concluirse que probablemente los jocistas, a diferencia de la etapa previa, no se vieron obligados a reafirmar su masculinidad católica porque no se sentían cuestionados por los obreros laicos, ni recurrían a metáforas bélicas sobre el protagonismo viril en la tarea de reconquista religiosa de la sociedad, ante una cultura conciliar que planteaba el diálogo con el mundo y el abandono de posiciones jerárquicas e impositivas. Por otro lado, en un momento de reafirmación de la juventud como colectivo con una identidad propia, como veremos, la masculinidad jocista no necesitaba

75 Sohn (2013: 24) comenta que el uso del masculino genérico y de lo masculino como norma general dificulta encontrar información sobre la masculinidad.

76 Juventud Obrera, núm. 111, 15 de octubre de 1966.

77 Juventud Obrera, núm. 96, julio de 1965. También en el comunismo hubo voluntad de aproximación a los cristianos, como muestra Treglia (2009).

78 Entrevistas a Santiago Barreras Milla y a Joan Moles Benet, cits. por Fernández Segura (2005): 228-229 y 236.

79 Babiano (1995) también señala que comunistas y cristianos compartían rasgos de sus culturas militantes. 
tampoco marcar sus rasgos frente a la infancia, al demostrar como jóvenes rebeldes y activos que ya no eran niños. En cuanto a su relación con el ideal femenino, antes tan subrayado, la experiencia de compartir numerosas iniciativas con sus compañeras jocistas permitió que el recurso a los discursos de la diferencia fuera perdiendo relevancia. Aunque en alguna ocasión se seguía recordando que aceptar la participación de las mujeres en la construcción de un mundo de justicia social no debía interpretarse como una falta de hombría de los obreros ${ }^{80}$, la insistencia en este tipo de argumentos fue desapareciendo, a pesar de las dudas y de la pervivencia de prácticas contradictorias.

La evolución del ideal de feminidad jocista fue muy acusada, de manera que nuevos discursos y prácticas fueron reconfigurando la identidad de las militantes de JOCF. En el ámbito religioso, es cierto que algunas voces reclamaron un reconocimiento de las mujeres en la Iglesia y subrayaron su condición de seglares activas, de acuerdo con los aires del Vaticano $\mathrm{II}^{81}$, pero los intereses de las jocistas derivaron más hacia el mundo obrero que hacia la pertenencia a una estructura eclesiástica de la que cada vez se sentían más autónomas ${ }^{82}$. Por el contrario, la identidad de las jocistas adquirió un inequívoco tono obrero, pues desde mediados de los años sesenta las militantes ya se percibían fundamentalmente como trabajadoras, que compartían con sus compañeras de taller o de fábrica, fueran católicas o no, valores como la responsabilidad, la honestidad y el orgullo por desempeñar bien su oficio. El trabajo se erigió en el eje de la vida de las jocistas, ya fuera entendido como fuente de autoestima y seguridad o como experiencia agotadora y discriminatoria, denunciándose en ese caso las largas jornadas laborales y la desigualdad salarial respecto a los hombres ${ }^{83}$.

De forma progresiva, se fue configurando una nueva identidad de joven trabajadora cristiana, que adquirió rasgos reivindicativos y desarrolló un discurso de la igualdad ${ }^{84}$. Aunque en algunos materiales de trabajo se seguía insistiendo en 1965 en la complementariedad y en que al chico «Le gusta dirigir y mandar; no le gusta que la chica le mande» ${ }^{85}$, las propias militantes expresaron de forma cada vez más decidida una actitud independiente y exigieron reconocimiento. En este sentido, Aida Fuentes, dirigente de la JOCF,

80 Juventudy Trabajo, núm. 34, mayo de 1965.

81 JOCF (sf): 91.

82 A diferencia de católicas adultas, que intentaron obtener reconocimiento en la Iglesia. Insiste en la diferencia entre generaciones en este debate Valiente (2015).

83 Juventud Obrera núms. 81-82, abril-mayo 1964 y núm. 84, julio 1964.

84 Con opiniones como: «no somos inferiores a él [el hombre]. Solo llevamos retroceso en el desarrollo intelectual», en Juventud y Trabajo, núm. 21, abril de 1964.

85 JOCF (1965): 68. 
afirmaba en 1964 que las jóvenes obreras deseaban participar en la vida en igualdad de condiciones respecto a otras mujeres y otras clases sociales, y reclamaban que sus problemas fueran escuchados, concluyendo de forma rotunda: «somos la misma clase obrera» ${ }^{86}$. Como recogen los testimonios orales, en la JOCF las militantes desarrollaron «un creixement de persona, que et doni més seguretat i més personalitat al davant dels teus problemas, no?, tant en el mon laboral com a casa seva» ${ }^{87}$, unos perfiles alejados de la anterior insistencia en la alegría o la ternura.

La formación crítica recibida en la JOCF y la adopción de compromisos les condujo a participar en las movilizaciones obreras y les convirtió con frecuencia en representantes sindicales, trasgrediendo los márgenes del discurso de género, del marco familiar y del control empresarial ${ }^{88}$. La escasa valoración de las trabajadoras en la cultura obrera era denunciada por algunas jocistas, que se quejaban del trato injusto y paternalista que a veces recibían de los hombres, quienes así «demuestran que son unos niños pequeños», y exigían una mayor autonomía: "¿Tenemos que esperar que sea el sexo fuerte el que nos resuelva la papeleta?»" Ante los problemas de las jóvenes trabajadoras, se afirmaba: «¿quién creemos que va a venir a solucionarlo? Solo nosotras» $»^{90}$. De manera paralela, algunas autoras indican que para obtener reconocimiento, en ocasiones las sindicalistas masculinizaron su forma de actuar, hablar y vestir ${ }^{91}$. En este sentido pueden interpretarse quizá algunas opiniones vertidas por mujeres de JOCF en la prensa al reclamar con "orgullo y valentía» su espacio en el mundo obrero y reafirmar su espíritu de lucha ${ }^{92}$. Este tipo de actitudes y opiniones, junto con prácticas que implicaban asumir riesgos y obtener prestigio en la movilización obrera, arrojaban nuevos referentes identitarios para las obreras cristianas, una imagen de las militantes que a veces era percibida como poco femenina ${ }^{93}$.

La JOCF impulsaba a las militantes no solo a erigirse en trabajadoras reivindicativas, sino también a convertirse en miembros activos de la sociedad.

86 Juventud Obrera, núm. 89, diciembre de 1964.

87 Entrevista a Conxita Roig Frasquet, Arxiu Històric de la CONC (AHCONC).

88 Martín y González (2011): 294-300.

89 Juventud Obrera, núm. 90, enero de 1965. Opiniones similares, expresadas por Conchita Valdés, en Juventud y Trabajo, núm. 30, enero 1965, y núm. 46, febrero de 1966.

90 Juventud y Trabajo, núm. 22, mayo de 1964. Sobre las dificultades de las mujeres para conseguir un trato igualitario en el mundo sindical, vid. Díaz Sánchez (2006).

91 Varo Moral (2014): 114-115.

92 Juventud Obrera, núm. 89, diciembre de 1964.

93 Según el testimonio de Ernestina Ródenas, recogido por Martínez Hoyos (2000): 207. 
Resulta sintomático que en el curso 1964-1965 la organización impulsara la campaña «Participemos en una sociedad en marcha». Primero con argumentos que recurrían a la maternidad, el cuidado y el amor, herederos en buena cuenta de la época previa, y después con un lenguaje igualitario, se llamaba a la acción y la autonomía. Aunque se advirtiera que la tarea de las mujeres no debía dejar de ser femenina, se utilizaba ya un lenguaje contundente cuando se rechazaba que la mujer obrera fuera considerada «en una perpetua minoría de edad ${ }^{94}$. Para lograr una mayor participación social de las jóvenes obreras, se exigía una preparación sólida, que sustentara una conciencia obrera, aunque esta reivindicación de manera paralela introducía contradicciones en el carácter obrero de la militancia, que revelan el miedo al desclasamiento.

Desde mediados de los años sesenta, los y las militantes de JOC/F comenzaron a percibirse como miembros de un colectivo generacional con identidad específica, en consonancia con el surgimiento de una cultura juvenil rebelde en el mundo occidenta ${ }^{95}$. Los análisis jocistas sobre la juventud española, que no se ceñían a su situación laboral sino que atendían aspectos como la educación, el ocio o las relaciones personales, señalaban la responsabilidad de las estructuras políticas y los intereses económicos para explicar problemas juveniles como el descontento y el consumismo. Consideraban rasgos positivos de la juventud su deseo de renovación, ansia de liberación y rebeldía ante lo constituido, tanto en hombres como en mujeres, pues la cultura juvenil de la época insistía cada vez menos en la diferencia sexual ${ }^{96}$. En su condición de jóvenes, reivindicaban que se les tuviera en cuenta, tanto en los ámbitos laborales como en la propia Iglesia. En este sentido pueden entenderse sus demandas de autonomía frente a la jerarquía eclesiástica, que interpretaba de manera negativa la creciente independencia y compromiso de la Acción Católica obrera, frente a los propios consiliarios y frente a los movimientos apostólicos de adultos, como la HOAC, organización que era vista como excesivamente rígida, aunque se colaborara con ella en defensa de la clase obrera y contra el franquismo ${ }^{97}$. De la misma manera, se dio una

94 Juventud Obrera, núm. 86, septiembre de 1964, y Juventudy Trabajo, núm. 27, octubre de 1964.

95 Como sucedió en otros países. En Alemania, también los movimientos católicos de juventud se vieron muy afectados por la nueva cultura juvenil, según Ruff (2005).

96 Juventudy Trabajo, núm. 27, octubre de 1964. Juventud Obrera, núm. 85, agosto de 1964 y núms. 87-88, octubre-noviembre de 1964.

97 Sobre las diferencias entre HOAC y JOC, vid. Castaño Colomer (1978): 109-111; Mauro Rubio, «Paso de la JOC a la HOAC», ANHOAC, Caja 227, carp. 5, o Texto de la Sección de Antiguos Jocistas, 1963 en ANHOAC, Caja 197, carp. 3. La demanda 
colaboración estrecha entre los distintos movimientos juveniles de AC, que reclamaban en 1965 derechos y cauces para una auténtica participación de la juventud en la sociedad ${ }^{98}$.

La importancia que adquirió la identidad juvenil se reflejó en el interés mostrado por el tiempo libre y el ocio, que ya no era analizado desde un prisma moral, sino desde la crítica a la frivolidad y la distracción de los problemas reales de la juventud. Frente a la música ye-yé o sentimental, se alababa la canción protesta, reflejo también de la politización del movimiento ${ }^{99}$. En términos cada vez más radicalizados, se afirmaba que «el joven trabajador es una víctima de todo un tinglado comercial y capitalista montado en torno a las diversiones, que impide su realización como persona y el avance de la clase obrera $»^{100}$. En consecuencia, además de las iniciativas desplegadas en la acción obrera, la JOC/F se interesó por mejorar la situación de los barrios populares, impulsó Centros de Cultura Popular y clubes juveniles, y organizó excursiones, actividades deportivas y culturales, iniciativas muy importantes en el aprendizaje ciudadano de muchos y muchas jóvenes bajo el franquismo ${ }^{101}$.

De forma paralela, la confluencia entre JOC y JOCF se fue afianzando, en los grupos de base y en actividades comunes cada vez más frecuentes, como la celebración del $1 .^{\circ}$ de mayo o la firma de manifiestos conjuntos en los que se demandaban mejoras laborales y derechos políticos $^{102}$. El trato en actividades apostólicas comunes, en las movilizaciones obreras y en momentos de ocio

de libertad de acción frente a la jerarquía y los consiliarios, por ejemplo en Documentación del Comité Ejecutivo de JOCF de octubre de 1966, ANJOC, Caja 26, carp. 1.8.8. Las tensiones debidas a la politización de las organizaciones y las diferencias generacionales afectaron también la Acción Católica francesa, aunque la JOC del país vecino debatió sobre la pervivencia de la clase obrera en un momento de auge de las clases medias, debate que en España todavía no se daba. Vid. Duriez et al. (2005): 38-42, entre otras.

98 En la Asamblea Nacional de la Juventud (Juventud Obrera, núm. 97, agosto de 1965). Trata el alcance de esta asamblea y las reacciones negativas de la jerarquía Montero (2005): 275-282.

99 Por ejemplo, en Juventud Obrera, núm. 112, 15 de noviembre de 1966, y núm. 115, marzo de 1967. No obstante, también se rechazaban algunas críticas a las diversiones y que se tildara a los jóvenes de "gamberros, afeminados, locos» (Juventud Obrera, núm. 93, abril de 1965).

100 Juventud Obrera, núm. 86, septiembre de 1964.

101 Martín y González (2011): 295-306.

102 Por ejemplo, Manifiesto de la JOC de Andalucía en Juventud Obrera, núm. 83, junio de 1964. Manifiesto de la JOC/F madrileña de 1969, AHCONC, Caja 48, carp. JOC. 
contribuyeron a reformular los ideales de género jocistas, de manera que con el tiempo disminuyó la atribución de valores diferenciados a mujeres y hombres, mientras se ensalzaban principios compartidos como la comprensión, la laboriosidad o la simpatía ${ }^{103}$. No obstante, los testimonios orales recuerdan que pervivían resistencias de los jocistas a la participación en igualdad de condiciones de sus compañeras; según Ernestina Ródenas, deseaban imponer sus opiniones, creían que ellas estaban poco preparadas y en alguna ocasión se negaban a ser acompañados por las militantes a actos públicos ${ }^{104}$. A pesar de estas contradicciones, el proceso culminó con la unificación de JOCF y JOC en una organización mixta, tras el acuerdo alcanzado en el Consejo de Santander en 1970, que se sustentaba en una representación equilibrada por sexos y en la posibilidad de seguir tratando cuestiones específicas, respondiendo así a algunos temores de la JOCF a su posible absorción por parte de la agrupación masculina ${ }^{105}$.

A medida que el interés del movimiento por las cuestiones sindicales y políticas aumentaba, se sucedieron los problemas con una jerarquía eclesiástica que se negaba a aceptar la autonomía y el compromiso temporal de la Acción Católica, que los y las jocistas reclamaban como seglares mayores de edad en la Iglesia ${ }^{106}$. Aunque las comisiones nacionales de JOC y JOCF no dimitieron durante la crisis que atravesó toda la Acción Católica entre 1966 y 1968, las organizaciones se vieron muy afectadas y sus boletines desaparecie$\operatorname{ron}^{107}$. En los Consejos Nacionales que tuvieron lugar en Ávila en 1967, se preguntaban si seguía siendo necesario un movimiento obrero apostólico; aunque la respuesta era positiva, el interrogante no parece retórico sino reflejo de los problemas que estaba atravesando la JOC/ $\mathrm{F}^{108}$. Como señala José Fernández Segura (2005: 286-287), la doble fidelidad a la Iglesia y a la clase obrera se

103 Juventud Obrera, núms. 107-108-109, 1 de agosto de 1966.

104 Entrevista a Ernestina Ródenas, cit. por Martínez Hoyos (2000): 207.

105 «Proyectos. Criterios fundamentales de unificación», XXIII Consejo Nacional de JOC y XIII Consejo Nacional de JOCF, ANJOC, Caja 4, carp. 1.2. Vid. también «Estudi sobre la unificació dels dos moviments JOC i JOCF», Arxiu Diocesà de Barcelona, Fons JOC Espanya, 3.14. Mostraron prevenciones similares las militantes de HOAC, como se observa en la Circular de la presidenta, 2 de diciembre de 1965, ANHOAC, Caja 345, carp. 6.

106 «Reflexiones de la JOC ante el comunicado del episcopado sobre el futuro de la AC», abril de 1967, reproducido en Castaño Colomer (1978): 149-150.

107 Para la crisis de la AC, vid. Montero (2000) y Murcia (1995).

108 «Revisión de Vida Obrera Nacional», XX Consejo Nacional de JOC y X Consejo Nacional de JOCF, ANJOC, Caja 3, carp. 1.4. 
convirtió en un dilema, debido a los conflictos con el episcopado, pero también a la urgencia de la militancia social y política. De hecho, según algunos testimonios, por esas fechas la organización ya no tenía un carácter cristiano, sino que su objetivo era potenciar el movimiento obrero, aunque probablemente no toda la militancia opinara igual ${ }^{109}$.

Se abrió a partir de entonces una etapa de dificultades que se prolongó a lo largo de toda la década de los setenta, y que supuso la erradicación del movimiento jocista de varias diócesis y la pérdida de buena parte de sus militantes, que en 1975 se limitaba a 850 jóvenes ${ }^{110}$. Las sucesivas tensiones internas de la JOC manifestaron una crisis de la identidad religiosa de la organización y de sus militantes, sin que puedan apreciarse diferencias entre mujeres y hombres ${ }^{111}$. A esta crisis contribuyeron las transformaciones sociales que debilitaron los referentes religiosos tradicionales, y el desprestigio de la Iglesia institucional española, percibida desde la JOC como aliada de los poderes políticos y económicos, y reacia a admitir la autonomía de los movimientos apostólicos ${ }^{112}$. En 1971, en la militancia jocista «el manifestarse como cristiano ante la lucha obrera resulta ridículo y vergonzoso» y «se empieza a pensar que la fe no sirve para nada ${ }^{113}$. Por otro lado, desde 1975 la propia JOC internacional se debatió entre la opción por un movimiento que primase la tarea evangelizadora y su pertenencia a la Iglesia, y otra que concedía más importancia a la tarea política y abría la JOC a jóvenes creyentes y no creyentes, controversia que se saldó con la escisión de la organización internacional y de la española en $1980^{114}$.

Frente a la crisis religiosa, la identidad obrera continuó muy firme en los setenta, pero ya muchos y muchas jocistas se cuestionaron su militancia en la propia JOC, ante la proliferación de sindicatos, movimientos sociales y formaciones políticas. Se trata de un proceso que tuvo lugar también en otros países europeos, pues en algunos casos los objetivos seculares prevalecieron sobre los

109 Entrevista a Salce Elvira Gómez, Fundación 1. Mayo, Fondo Biografías Obreras.

110 «Informe sobre la JOC», XXVIII Consejo Nacional de la JOC, ANJOC, Caja 6, carp. 1.1.1.

111 A diferencia de lo sucedido en la HOACF, donde un sector importante de la militancia se alejó de la evolución de la HOAC y la JOC/F hacia una fe crítica e independiente de la jerarquía, según Moreno Seco (2011).

112 "Análisis de la situación de la Juventud Obrera», Almansa, 26-27 de septiembre de 1970, Archivo de la Democracia-Universidad de Alicante (ADUA), Dossier JOC.

113 "Conversaciones en Murcia de consiliarios jocistas», marzo de 1971, ADUA, Dossier JOC.

114 González de la Cruz (2002): 605-606. 
religiosos, la existencia de organizaciones cristianas perdió sentido y tuvo lugar una confluencia con otras fuerzas en sindicatos y partidos ${ }^{115}$. En ese contexto, la documentación interna y la prensa de la JOC mixta parecen reflejar una evolución de las identidades y de las relaciones de género similar a la que tuvo lugar en agrupaciones sindicales como CC. OO. En unos primeros años la premura de la lucha laboral y antifranquista creó una imagen de activismo igualitario que ocultó las jerarquías de género ${ }^{116}$, aunque se recurriera en los textos al masculino genérico de «jóvenes trabajadores» y a pesar de que las mujeres quedaran excluidas de los puestos de poder de primer orden, pues los cargos de presidente de JOC fueron ocupados por varones ${ }^{117}$. Desde mediados de los setenta las reivindicaciones de las mujeres y su protagonismo en las movilizaciones obreras se hicieron más visibles ${ }^{118}$. Con límites y contradicciones, la JOC incorporó entonces alusiones concretas a la realidad de las mujeres y representó la militancia con imágenes tanto masculinas como femeninas ${ }^{119}$.

En la compleja interacción de identidades que hemos expuesto, la categoría de juventud se convirtió en un eje fundamental de la JOC durante los años setenta, hecho que explica su colaboración con otras organizaciones juveniles progresistas, con frecuencia vinculadas a la nueva izquierda. No obstante, también se ha planteado la existencia de una crisis del modelo de militancia, muy vinculado a la cultura juvenil que en todo el mundo occidental sostuvo proyectos contestatarios. Como ha apuntado Francisco Martínez Hoyos (2013: 434), las organizaciones católicas se vieron afectadas por estos cambios y frente al anterior ideal del trabajador sacrificado y austero, se extendió una nueva forma de militar, influida por el mayo del 68, que incorporaba elementos como la imaginación, el placer y la sexualidad ${ }^{120}$. Las críticas al capitalismo, con un lenguaje plenamente marxista, y a la opresión sexual se extendieron en la JOC ${ }^{121}$. Creció

115 Pasture y Kenis (2010): 10-14.

116 Como comenta para CC. OO. Babiano (2007): 45-46.

11 En 1970, era presidente Julián López y secretaria Salce Elvira, mientras en 1977 la presidencia estaba ocupada por Teófilo Rodríguez y la secretaría por Marina Márquez (vid. correspondencia variada en ANJOC, Caja 4, carp. 1.3. y Caja 6, carp. 1.3.3.).

118 Varo Moral (2014): 124-126.

119 Como muestra, el número de Juventud Obrera de diciembre de 1976 (núm. 119) alude por igual a las consecuencias del paro entre las trabajadoras y los trabajadores, o denuncia el trato sexista de la imagen de mujeres y hombres en los cómics.

120 Una liberación sexual que tenía en esa época una lectura política, Kornetis (2015).

121 Por ejemplo, críticas al modo de producción neocapitalista, la represión política, al machismo y la represión sexual en el «Balance del curso 1970-1971», XXIV Consejo Nacional de JOC, Murcia, ANJOC, Caja 4, carp. 1.3. 
el interés por las propuestas feministas, aunque muchas jocistas no se implicaron en el movimiento de mujeres, según Varo (2014: 126) porque después del esfuerzo desplegado para crear organizaciones mixtas, percibían como anacrónicas las organizaciones de mujeres.

\section{CONCLUSIONES}

La evolución de las identidades de género en la JOC revela los diferentes caminos que a lo largo de los años sesenta transitaron las nociones de feminidad y masculinidad en dicho movimiento, hacia una creciente confluencia en modelos bastante próximos. Conforme avanzaba la década, la crisis religiosa, la integración en el movimiento obrero, la influencia de los discursos igualitarios y la urgencia de la lucha antifranquista permitieron que las fronteras identitarias de género se matizaran y flexibilizaran, de manera que las militantes de JOCF acabaron reclamando un espacio en el mundo del trabajo y se alejaron del ideal piadoso y hogareño que había sustentado el catolicismo tradicional, a la vez que los jocistas dejaron de reafirmar su identidad masculina católica, en un contexto de auge de unos referentes identitarios juveniles que incorporaban la igualdad como valor. En esta etapa se detectan por tanto varias resignificaciones en las identidades de género: de cruzado en defensa de la religión a obrero en lucha por sus derechos, y de futura esposa y madre a trabajadora implicada en el movimiento obrero. De manera que ambas identidades incorporaron o reforzaron valores propios de la cultura obrera, como arrojo, sacrificio y lucha, que entroncaban con el compromiso social impulsado por el Vaticano II. En un contexto de intensa movilización juvenil, de contacto con referentes simbólicos trasgresores y nuevas costumbres, las identidades católicas y de género cedieron paso a las identidades de clase y de edad.

La identidad religiosa jocista se vio seriamente cuestionada a medida que los años sesenta se encaminaban a su fin y de forma plena en los setenta. La crisis religiosa de la JOC estuvo provocada por factores externos, como la irrupción de la contracultura juvenil, el desarrollo de una nueva identidad femenina alejada de los anteriores patrones morales o la emergencia de la acción política y sindical, y por elementos internos, como los conflictos con la jerarquía. Estos cambios afectaron tanto a mujeres como a hombres, que abandonaron la Iglesia y a veces incluso la fe, o se decantaron por otras formas de vivir la religión. En consecuencia, la experiencia de la JOC parece apuntar que el debate sobre la feminización o masculinización de la religión se saldó en este caso concreto con el fin de las diferencias de género en las maneras de 
sentir y manifestar las creencias religiosas, una homogeneización a la que no fue ajeno el carácter obrero y juvenil de JOC.

En este texto se ha optado por observar cómo se modularon la masculinidad y la feminidad católicas en función de las relaciones entre los y las militantes de JOC y JOCF, pero quedan abiertos a nuevas investigaciones aspectos que aquí solo se han mencionado, como las tensiones identitarias surgidas frente a los adultos y adultas de HOAC, a la militancia de clase media de las organizaciones juveniles de Acción Católica, e incluso a los consiliarios y el clero. Estas y otras cuestiones pueden contribuir a conocer mejor las reformulaciones de las identidades católicas de género en un sentido menos jerárquico y más inclusivo, y a entender las experiencias de numerosas personas que en su juventud participaron, desde un movimiento de Iglesia, en los cambios sociales y culturales que difundieron valores igualitarios y democráticos, y que acabarían haciendo inviable la dictadura franquista.

\section{Bibliografía}

Arbaiza, M. (2014). Obreras, amas de casa y mujeres liberadas. Trabajo, género e identidad obrera en España. En M. Nash (ed.). Feminidades y masculinidades. Arquetipos y prácticas de género (pp. 129-157). Madrid: Alianza.

Babiano, J. (1995). Los católicos en el origen de Comisiones Obreras. Espacio, Tiempo y Forma. Serie V-Historia Contemporánea, 8, 277-293.

- (2007). Mujeres, trabajo y militancia laboral bajo el franquismo (materiales para un análisis histórico). En J. Babiano (ed.). Del hogar a la huelga. Trabajo, género y movimiento obrero durante el franquismo (pp. 25-75). Madrid: Libros de la Catarata.

Berzal de la Rosa, E. (2007). Católicos en la lucha antifranquista. Militancia sindical y política. Historia del Presente, 10, 7-24.

Blasco Herranz, I. (2003). Paradojas de la ortodoxia. Política de masas y militancia católica femenina en España (1919-1939). Zaragoza: Prensas Universitarias.

— (2005). Género y religión: de la feminización de la religión a la movilización católica femenina. Una revisión crítica. Historia Social, 53, 119-136.

Brown, C. G. (2010). What was the Religious Crisis of the 1960s? Journal of Religious History, 34 (4), 468-479. Disponible en: https://doi.org/10.1111/j.1467-9809.2010.00909.x.

- (2013). Gender, Christianity and the Rise of No Religion: The Heritage of the Sixties in Britain. En N. Christie y Mi. Grauveau (eds.). The Sixties and Beyond. Dechristianization in North America and Western Europe, $1945-2000$ (pp. 39-59). Toronto: University of Toronto Press.

Castaño Colomer, J. (1978). La JOC en España (1946-1970). Salamanca: Sígueme.

Cazorla-Sánchez, A. (2013). A Different Path? National Catholicism, Laicization and Dechristianization in Spain, 1939-1975. En N. Christie and M. Grauveau (eds.). The 
Sixties and Beyond. Dechristianization in North America and Western Europe, 19452000 (pp. 351-366). Toronto: University of Toronto Press.

Connell, R. W. (2003). La organización social de la masculinidad. En C. Lomas (comp.). ¿Todos los hombres sois iguales? Identidades masculinas y cambios sociales (pp. 31-54). Barcelona: Paidós.

De la Cueva Merino, J. (2015). Conflictiva secularización: sobre sociología, religión e historia. Historia Contemporánea, 51, 356-395. Disponible en: https://doi.org/10.1387/ hc. 14712 .

Díaz Sánchez, P. (2006). Disidencias y marginaciones de las mujeres en el sindicalismo español. Sociología del Trabajo, 56, 101-116.

Domènech Sampere, X. (2008). Temps d'insertesscions. La Joventut Comunista de Catalunya (1970-1980). Barcelona: Fundació Francesc Ferrer i Guàrdia.

Duriez, B. et al. (2005). Les catholiques dans la République, 1905-2005. París: Les éditions de l'atelier/Éditions Ouvrières.

Erice Sebares, F. (2010). El «orgullo de ser comunista». Imagen, autopercepción, memoria e identidad colectiva de los comunistas españoles. En M. Bueno y S. Gálvez (ed.). Nosotros, los comunistas. Memoria, identidad e historia social (pp. 139-183). Madrid: FIM.

Favier, A. (2009). Des religieuses féministes dans les années 68? Clio. Femmes, Gendre, Histoire, 29, 59-77.

(2012). L'enjeu de la mixité dans un autre mouvement de jeunesse catholique: JOC et JOCF. Une approche historique. Comunicación presentada en el Congreso Eduquer des garçons et des filles. La question du genre au coeur des pratiques educatives. Disponible en: https://halshs.archives-ouvertes.fr/halshs-00731504.

Fernández Segura, J. (2005). La participación de los católicos en el movimiento obrero en Barcelona (1946-1978) [tesis doctoral]. Universitat de Barcelona. Disponible en : http:// www.tdx.cat/handle/10803/1984.

Fouilloux, E. (1995). Femmes et catholicisme dans la France contemporaine. Clio. Histoire, femmes et sociétés, 2, 319-329. Disponible en : https://doi.org/10.4000/clio.498.

González de la Cruz, J. (2002). Obreros y cristianos: la JOC durante la Transición (19751980). En C. Navajas Zubeldia (ed.). Actas del III Simposio de Historia Actual (pp. 601612). Logroño: Instituto de Estudios Riojanos.

Horn, G-R. (2015). The Spirit of Vatican II: Western European Left Catholicism in the long sixties, 1959-1980. Oxford: Oxford University Press. Disponible en: https://doi. org/10.1093/acprof:oso/9780199593255.001.0001.

JOC (1963). Por una mayor conciencia y dignidad obrera. Encuesta Campaña Nacional JOC 1963-64. Madrid: JOC.

(1965). Tú y el servicio militar. Valencia: JOC.

JOCF (sf). En los umbrales de la vida adulta. Madrid: Publicaciones JOCF.

— (1965). Asi comienza la JOCF. Madrid: Publicaciones JOCF.

Kornetis, K. (2015). «Let's get laid because it's the end of the world»: sexuality, gender and the Spanish Left in late Fracoism and the Transición. European Review of History, 22 (1), 176-198. Disponible en: https://doi.org/10.1080/13507486.2014.983433.

Llona, M. (2007). Los otros cuerpos disciplinados. Relaciones de género y estrategias de autocontrol del cuerpo femenino (primer tercio del siglo xx). Arenal, 14 (1), 79-108. 
López García. B. (1995). Aproximación a la historia de la HOAC. Madrid: HOAC.

Louzao Villar, J. y Montero García, F. (coords) (2015). La restauración social católica en el primer franquismo, 1939-1953. Alcalá: Universidad de Alcalá de Henares.

Martín García, O. J. y González Madrid, D. A. (2011). La aportación católica a la crisis del franquismo y a la construcción de una sociedad democrática. Nuevas perspectivas de análisis micro. En M. Ortiz y D. A. González (coords.). De la cruzada al desenganche: la Iglesia española entre el franquismo y la transición (pp. 291-315). Madrid: Sílex.

— y Ortiz Heras, M. (2009). «Envenenando a nuestra juventud». Cambio de actitudes y militancia juvenil en el segundo franquismo. Historia Actual On Line, 20, 19-33.

Martín Serrano, M. (ed.) (1994). Historia de los cambios de mentalidades de los jóvenes entre 1960-1990. Madrid: Instituto de la Juventud-Ministerio de Asuntos Sociales.

Martínez Hoyos, F. (2000). La JOC a Catalunya (1947-1975). Els senyals d'una Església del demà. Barcelona: Mediterrània.

- (2001). Un moviment oblidat: la Joventut Obrera Cristiana Femenina. En Franquisme itransició democràtica a les terres de parla catalana (pp. 225-239). Barcelona: Cossetània.

- (2013). Mayo del 68 y los católicos catalanes. Hispania Sacra, 131, 425-445. Disponible en: https://doi.org/10.3989/hs.2013.013.

Marwick, A. (1998). The Sixties. Cultural Revolution in Britain, France, Italy and the United States. Oxford: Oxford University Press.

McLeod, H. (2007). The Religious Crisis of the 1960s. Oxford: Oxford University Press. Disponible en: https://doi.org/10.1093/acprof:oso/9780199298259.001.0001.

- (2010). The Present Crisis in Historical Context. En L. Kenis, J. Billiet y P. Pasture (eds.). The Transformation of Christian Churches in Western Europe (pp. 23-38). Leuven: Leuven University Press.

Mínguez Blasco, R. (2015). ¿Dios cambió de sexo? El debate internacional sobre la feminización de la religión y algunas reflexiones para la España decimonónica. Historia Contemporánea, 51, 397-426. Disponible en: https://doi.org/10.1387/hc.14714.

Montero, F. (1987). Juventud y política. Los movimientos juveniles de inspiración católica en España, 1920-1970. Studia Historica. Historia Contemporánea, 5, 105-121.

- (2000). La Acción Católica y el franquismo. Auge y crisis de la Acción Católica especializada. Madrid: UNED.

- (2005). Los movimientos juveniles de Acción Católica. De la militancia apostólica al compromiso político. En J. M. Castells, J. Hurtado y J. M. Margenat (coords.). De la dictadura a la democracia: la acción de los cristianos en España (1939-1975) (pp. 263293). Bilbao: Desclée de Brouwer.

- (2009). La Iglesia: de la colaboración a la disidencia (1956-1975). Madrid: Encuentro.

Morcillo, A. G. (2000). True Catholic Womanhood. Gender Ideology in Franco's Spain. DeKalb: Northern Illinois University Press.

Moreno Seco, M. (2003). Cristianas por el feminismo y la democracia. Catolicismo femenino y movilización en los años setenta. Historia Social, 53, 137-153.

- (2011). Mujeres, trabajadoras y católicas: la HOACF en el franquismo. En M. Ortiz y D. González (coords.). De la cruzada al desenganche: la Iglesia española entre el franquismo y la transición (pp. 133-159). Madrid: Sílex. 
- (2016). Jóvenes trabajadoras cristianas: compromiso social y aprendizaje ciudadano en la JOC. Ayer, 102, 95-119.

— y Ortuño Martínez, B. (2015). Dosier Género, juventud y compromiso. Ayer, 100.

Muller, C. y Favier, A. (2013). Les Hommes catholiques, un point aveugle des études de genre? Réflexions sur l'étude des masculinités en contexte catholique (France, XIXe$\mathrm{XXe}$ ). Comunicación presentada en el Coloquio Histoire des femmes, histoire du genre, histoire genrée. Disponible en : http://consciences.hypotheses.org/530.

Muñoz Ruiz, M. C. (2007). Género, masculinidad y nuevo movimiento obrero bajo el franquismo. En J. Babiano (ed.). Del hogar a la huelga. Trabajo, género y movimiento obrero durante el franquismo (pp. 245-285). Madrid: Libros de la Catarata.

Murcia, A. (1995). Obreros y obispos en el franquismo. Estudios sobre el significado eclesiológico de la crisis de la Acción Católica Española. Madrid: HOAC.

Nash, M. (2010). Trabajadoras: un siglo de trabajo femenino en Cataluña (1900-2000). Barcelona: Generalitat de Catalunya.

(2015). Mass Tourism and New Representations of Gender in Late Francoist Spain: The Sueca and Don Juan in the 1960s. Cultural History, 4 (2), 136-161. Disponible en: https://doi.org/10.3366/cult.2015.0091.

Ortiz, M. y González, D. (coords.) (2011). De la cruzada al desenganche: la Iglesia española entre el franquismo y la transición. Madrid: Sílex.

Pasture, P. (2012). Beyond the feminization thesis. Gendering the History of Christianity in the Nineteenth and Twentieth Centuries. En P. Pasture, J. Art, y T. Buerman (eds.). Beyond the Feminization Thesis and Gender Christianity in Modern Europe (pp. 7-32). Leuven: Leuven University Press.

Patrick, P. y Kenis, L. (2010). The Transformation of Christian Churches in Western Europe. An Introduction. En L. Kenis, J. Billiet y P. Pasture (eds.). The Transformation of Christian Churches in Western Europe (pp. 7-20). Leuven: Leuven University Press.

Pérez Ledesma, M. (2008). La construcción de las identidades sociales. En J. Beramedi y M. J. Baz (eds.). Identidades y memoria imaginada (pp. 19-41). Valencia: Universitat de València.

Rauch, A. (2004). L'identité masculine à l'ombre des femmes. De la Grande Guerra à la Gay Pride. París: Hachette.

Ruff, M. E. (2005). The Wayward Flock. Catholic Youth in Postwar West Germany, 19451965. Chapel Hill and London: The University of North Carolina Press.

Salomón Chéliz, P. (2011). Devotas mojigatas, fanáticas y libidinosas. Anticlericalismo y antifeminismo en el discurso republicano a fines del siglo XIX. En A. Aguado y T. M. Ortega (eds.). Feminismos y antifeminismos. Culturas politicas e identidades de género en la España del siglo XX (pp. 71-98). Valencia: PUV.

Sanz Fernández, F. (1994). La aportación de la JOC a la cultura obrera y a la formación de militantes para el movimiento obrero. XX Siglos, 22, 46-60.

Sohn, A. M. (2013). Introduction. Les hommes ont-ils une historie? En A. M. Sohn (dir.). Une Historie sans les hommes est-ce possible? Genre et masculinité (pp. 7-27). Lyon: ENS Éditions.

Souto Kustrín, S. (2007). Juventud, teoría e historia: la formación de un sujeto social y de un objeto de análisis. Historia Actual On Line, 13, 171-192. 
Sun, R. C. (2004). «Hammer Blows»: Work, the Workplace, and the Culture of Masculinity Among Catholic Workers in the Weimar Republic. Central European History, 37 (2), 245-271. Disponible en: https://doi.org/10.1163/156916104323121474.

Treglia, E. (2009). Quando la religione cessa di essere l'oppio dei popoli: il PCE e i tentativi di avvicinamento ai cattolici degli anni sessanta. Spagna Contemporanea, 35, 101-117.

Valiente, C. (2007). «Consecuencias» no es sinónimo de «éxito»: La movilización feminista en la Iglesia católica en España durante el franquismo. En P. Amador Carretero y R. Ruiz Franco (eds.). La otra dictadura: El régimen franquista y las mujeres (pp. 415426). Madrid: Universidad Carlos III de Madrid.

— (2015). Age and Feminist Activism: The Feminist Protest Within the Catholic Church in Franco's Spain. Social Movement Studies: Journal of Social, Cultural and Political Protest, 14 (4), 473-492. Disponible en: https://doi.org/10.1080/14742837.2014.947252.

Van Osselaer, T. (2009). Christening Masculinity? Catholic Action and Men in Interwar Belgium. Gender \& History, 21 (2), 380-401. Disponible en: https://doi.org/10.1111/ j.1468-0424.2009.01554.x.

- (2013). The Pious Sex: Catholic Constructions of Masculinity and Femininity in Belgium, c.1800-1940. Leuven: Leuven University Press.

Varo Moral, N. (2014). Las militantes ante el espejo. Clase y género en las CC.OO. del área de Barcelona (1964-1978). Alzira: Germania.

Vincent, M. (2015). La masculinidad en la construcción del nacional-catolicismo después de la Guerra Civil. Ponencia presentada en el VI Seminario Internacional de AEIHM Feminidades y masculinidades en la Historiografía de Género.

Werner, Y. M. (ed.) (2011). Christian Masculinity. Men and Religion in Northern Europe in the 19th and 20th Centuries. Leuven: Leuven University Press. 